\title{
Assessing Cluster Models of Solvation for the Description of Vibrational Circular Dichroism Spectra: Synergy between Static and Dynamic Approaches
}

Katia Le Barbu-Debus, ${ }^{\text {a) }}$ Jessica Bowles, ${ }^{\text {b) }}$ Sascha Jähnigen, ${ }^{c)}$ Carine Clavaguéra, ${ }^{\text {b) }}$ Florent Calvo, ${ }^{\text {d) }}$ Rodolphe Vuilleumier, ${ }^{\text {c) }}$ Anne Zehnacker ${ }^{\text {a) }}$

a) Institut des Sciences Moléculaires d'Orsay (ISMO), CNRS, Université Paris-Saclay, F91405 Orsay, France

b) Université Paris-Saclay, CNRS, Institut de Chimie Physique, UMR8000, 91405 Orsay, France

c) PASTEUR, Département de Chimie, Ecole Normale Supérieure, PSL University, Sorbonne Université, CNRS, 75005 Paris, France

d) Laboratoire Interdisciplinaire de Physique (LiPhy), CNRS, Université Grenoble Alpes, 140 Avenue de la Physique - BP 8738402 Saint Martin d'Hères, France

\section{Supplementary Information}




\begin{tabular}{|c|c|c|c|}
\hline & $\Delta \mathrm{G}$ & $E_{0}$ & $\mathrm{E}_{0}+\mathrm{ZPE}$ \\
\hline bi-eqg $^{+} \mathrm{G}^{-}$ & 0.0 & 0.0 & 0.0 \\
\hline mono $_{\mathrm{OH}^{-}}$eqg $^{-}$ & 1.4 & 3.3 & 2.0 \\
\hline mono $_{\mathrm{OH}^{-}}$eqg G ${ }^{+}$ & 2.0 & 5.3 & 4.3 \\
\hline 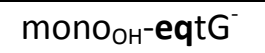 & 2.4 & 3.9 & 3.3 \\
\hline mono ${ }_{\mathrm{OH}^{-}}$-eqg $\mathrm{T}$ & 3.4 & 6.2 & 5.0 \\
\hline noHB-eqg $^{+} \mathrm{G}^{+}$ & 3.4 & 26.4 & 22.9 \\
\hline bi-eqg $^{+} T$ & 4.1 & 3.1 & 2.9 \\
\hline $\mathrm{mono}_{\mathrm{OH}^{-}}{ }^{-\operatorname{axg}^{+} T}$ & 4.7 & 9.4 & 8.2 \\
\hline mono $_{\mathrm{OH}^{-}}$-eqtT & 6.8 & 7.7 & 7.4 \\
\hline mono $_{\mathrm{NH}^{-}}$eqg $^{+} \mathrm{G}^{+}$ & 10.8 & 17.6 & 15.8 \\
\hline mono $_{\mathrm{OH}^{-}}$eqg $^{+} \mathrm{G}^{+}$ & 12.7 & 4.0 & 3.5 \\
\hline $\mathrm{mono}_{\mathrm{OH}^{-}}-\mathrm{axtG}^{-}$ & 13.7 & 11.9 & 11.7 \\
\hline $\mathrm{mono}_{\mathrm{OH}}-\mathrm{axtT}$ & 16.2 & 15.2 & 14.5 \\
\hline
\end{tabular}

Table S1: Comparison between Gibbs free energies $\Delta G$ at room temperature, electronic energies $E_{0}$ at $0 K$, and ZPE-corrected electronic energies at $0 K(\mathrm{~kJ} / \mathrm{mol}) E_{0}+Z P E$, for the most stable 1-1 complexes calculated at the B3LYP/6-311++G(d,p) level. 


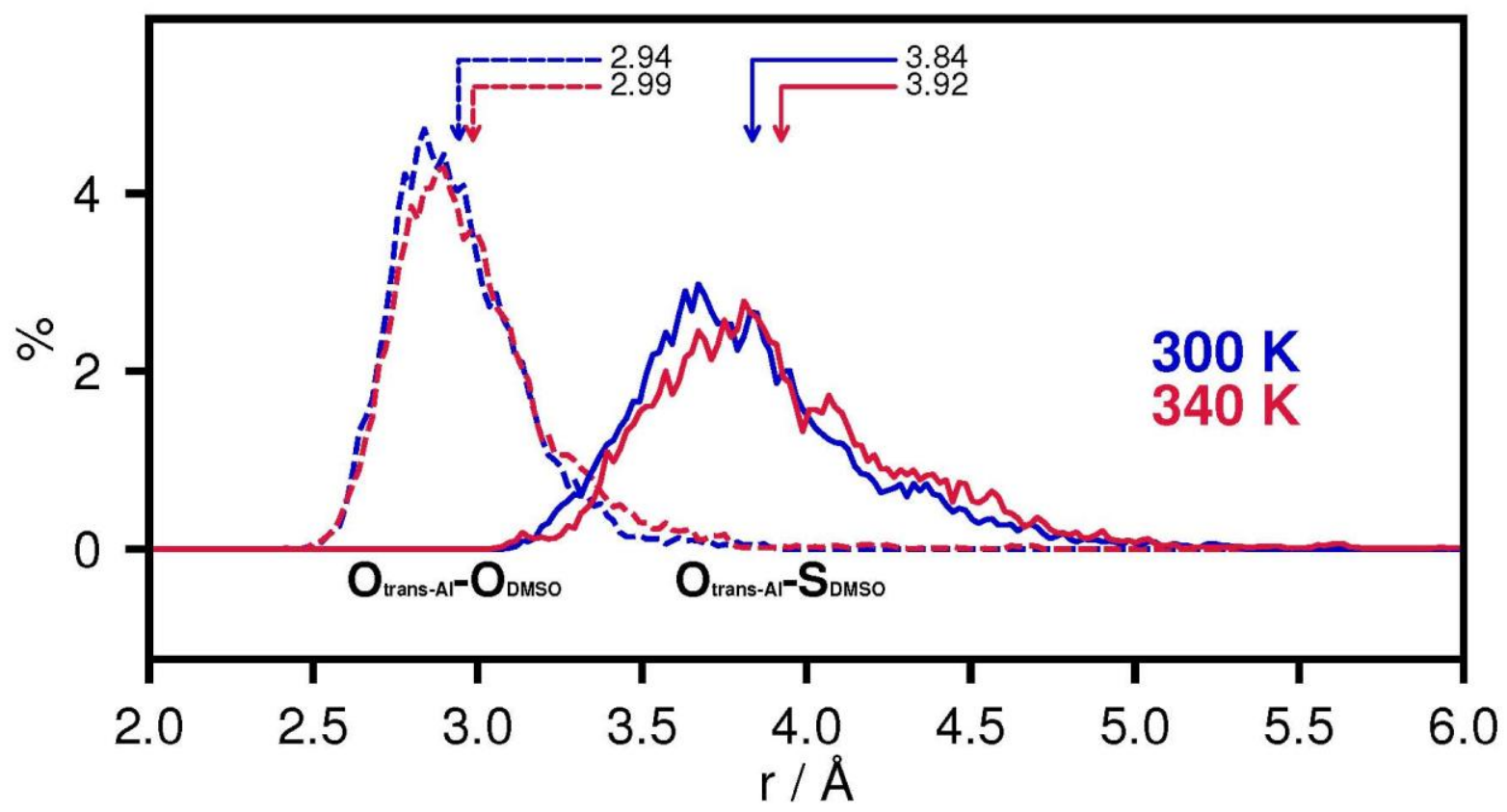

Figure S1: Distribution of distance between the oxygen atom of trans-Al and the oxygen/sulfur atom of DMSO, obtained from the FPMD trajectories at different temperatures (BLYP-D3). 


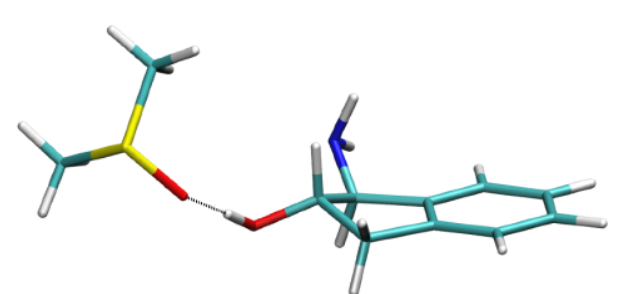

$\operatorname{mono}_{\mathrm{OH}^{-}} \mathbf{e q} g^{-} G^{+}: 2.0 \mathrm{~kJ} \cdot \mathrm{mol}^{-1}$

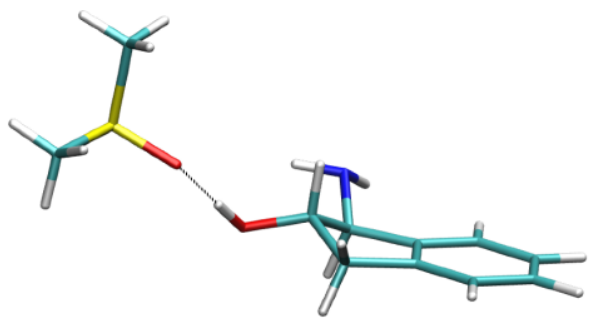

$\operatorname{mono}_{O H}$-eq $g^{-} T: 3.4 \mathrm{~kJ} \cdot \mathrm{mol}^{-1}$

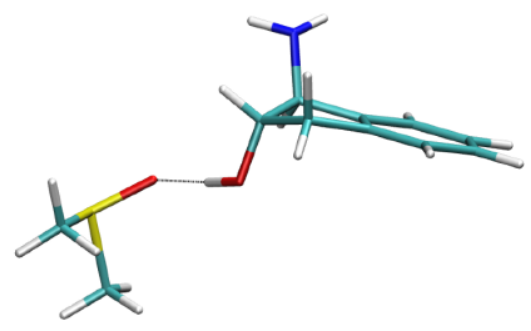

$\operatorname{mono}_{O H^{-}} \mathbf{a x} g^{+} T: 4.7 \mathrm{~kJ} \cdot \mathrm{mol}^{-1}$

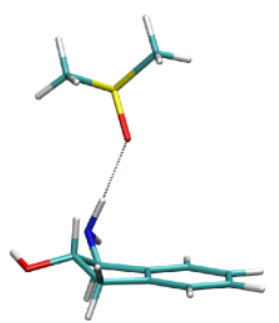

$\operatorname{mono}_{\mathrm{NH}^{-}} \mathbf{e q} g^{+} G^{+}: 10.8 \mathrm{~kJ} \cdot \mathrm{mol}^{-1}$

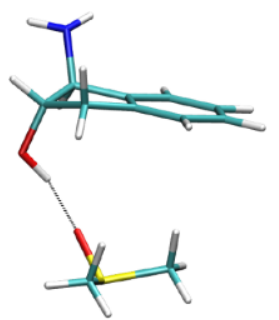

$\operatorname{mono}_{O H}-\operatorname{ax} t T: 16.2 \mathrm{~kJ} \cdot \mathrm{mol}^{-1}$

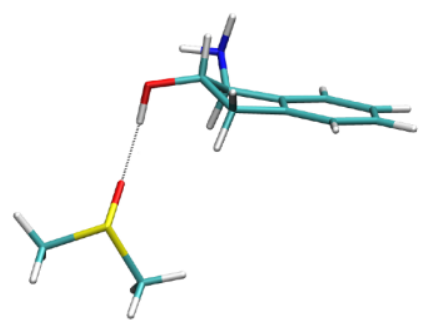

$\operatorname{mono}_{O H^{-}}$eq $t G^{-}: 2.4 \mathrm{~kJ} \cdot \mathrm{mol}^{-1}$

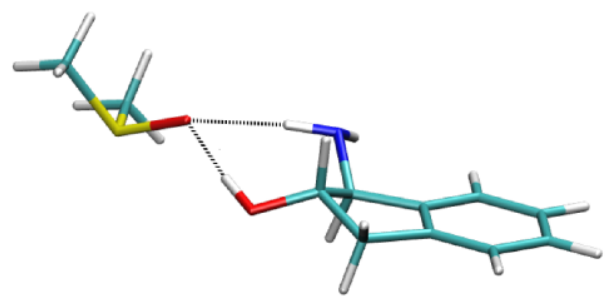

bi-eq $g^{+} T: 4.1 \mathrm{~kJ} \cdot \mathrm{mol}^{-1}$

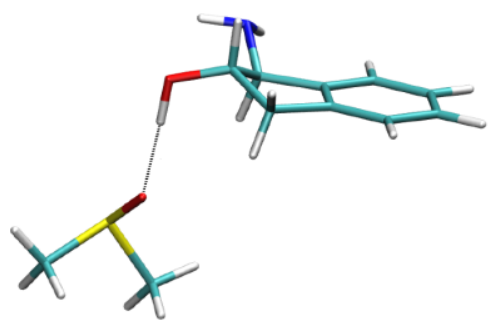

mono $_{O H}$ eq $t T: 6.8 \mathrm{~kJ} \cdot \mathrm{mol}^{-1}$

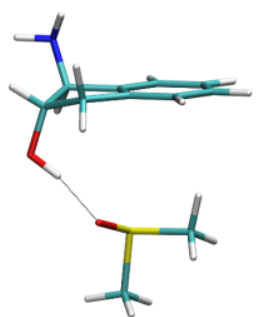

$\operatorname{mono}_{O H}-\operatorname{ax} t G^{-}: 13.7 \mathrm{~kJ} \cdot \mathrm{mol}^{-1}$

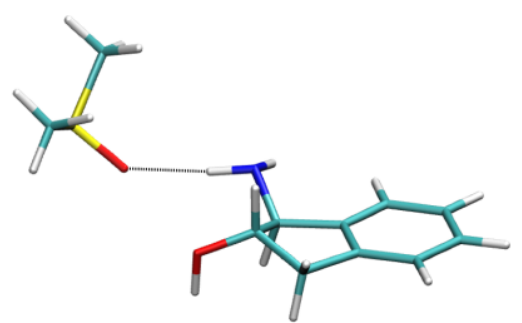

$\operatorname{mono}_{N H^{-}} \mathbf{e q} t T: 20.8 \mathrm{~kJ} \cdot \mathrm{mol}^{-1}$

Figure S2: Stable calculated structure of the trans-Al:DMSOd 6 1:1 complex at the B3LYP/6$311 \mathrm{G}++(d, p)$ level in a DMSO continuum. 


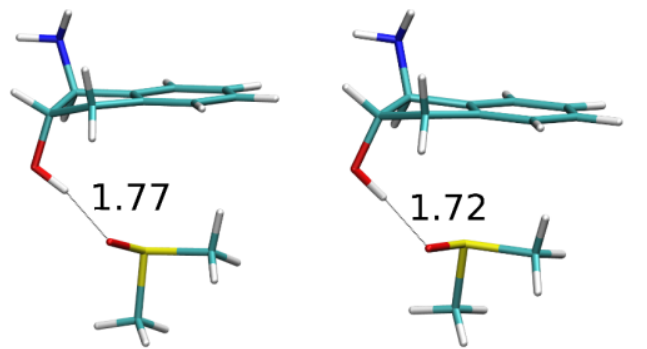

$\operatorname{mono} O H^{-a x} t G^{-}$

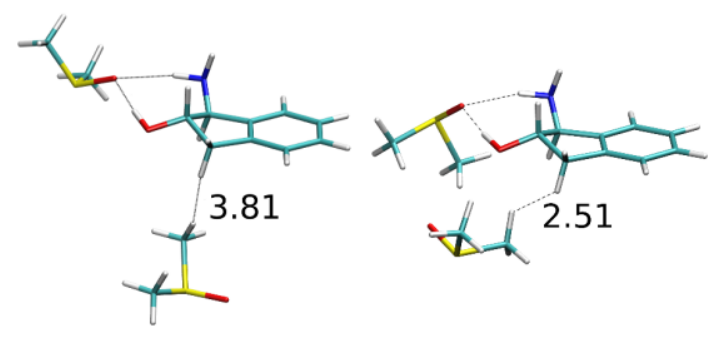

dmso-bi-eq $g^{+} G^{-}$

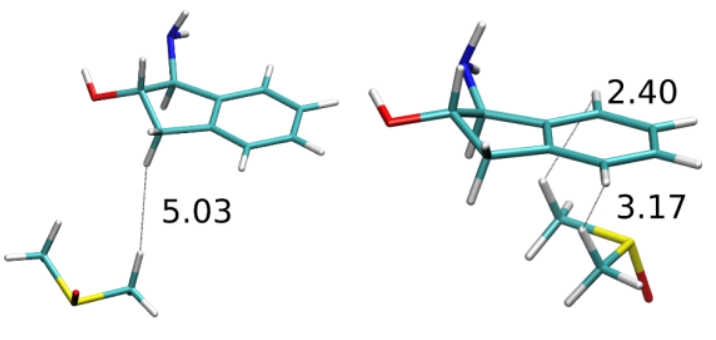

noHB-eq $g^{+} G^{+}$

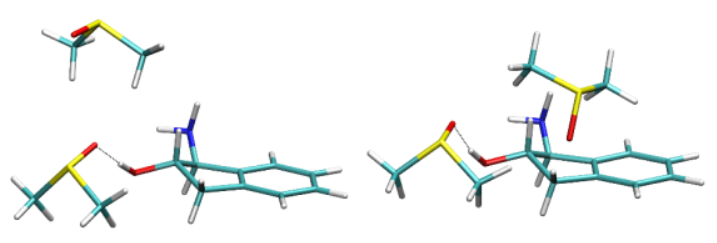

dmso-mono $\mathrm{OH}^{-} \mathbf{e q} g^{-} G^{-}$

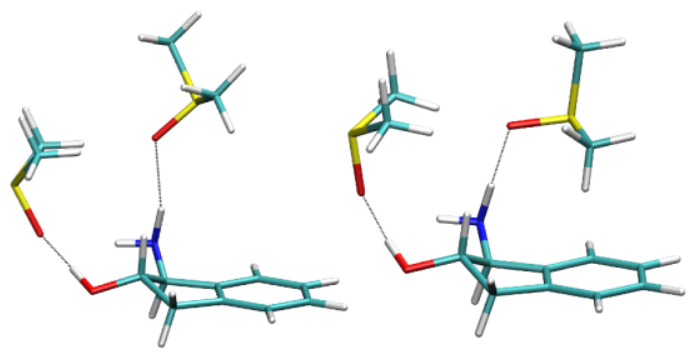

monoOH-mono $_{N H^{-}}$eq $g^{+} G^{-}$

Figure S3: Comparison between the geometry calculated at the B3LYP/6-311G++(d,p) level without (left) or with (right) dispersion correction for a selection of trans-Al:(DMSOd 6 ) 1:1 and trans-Al:(DMSOd $)_{2}$ 1:2 complexes. 


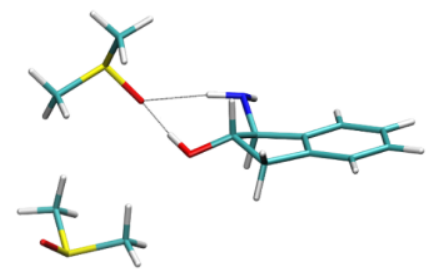

dmso-bi-eq $g^{+} T: 1.6 \mathrm{~kJ} \cdot \mathrm{mol}^{-1}$

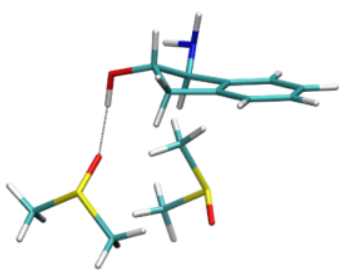

dmso-monooH-eq $t G^{-}: 3.1 \mathrm{~kJ} \cdot \mathrm{mol}^{-1}$
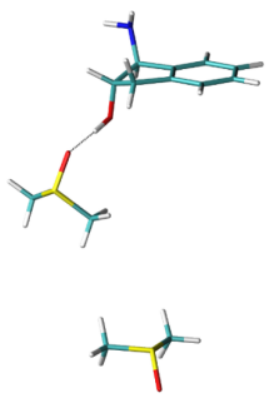

dmso-mono $O H^{-}$ax $g^{-} G^{-}: 6.6 \mathrm{~kJ} \cdot \mathrm{mol}^{-1}$
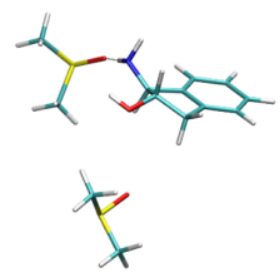

dmso-mono $\mathrm{NH}^{-}$eq $g^{+} G^{+}: 6.9 \mathrm{~kJ} \cdot \mathrm{mol}^{-1}$

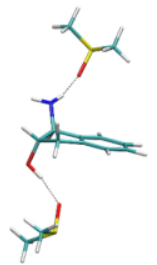

$\operatorname{mono}_{\mathrm{OH}}-\mathrm{mono}_{\mathrm{NH}}-\mathrm{ax} t T: 15.7 \mathrm{~kJ} \cdot \mathrm{mol}^{-1}$
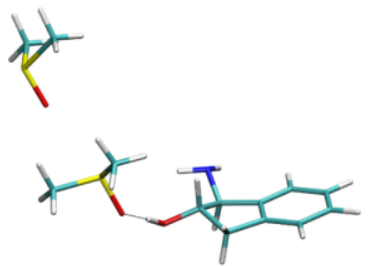

dmso-mono $\mathrm{OH}^{-\mathbf{e q}} g^{-} \mathrm{T}: 2.3 \mathrm{~kJ} \cdot \mathrm{mol}^{-1}$

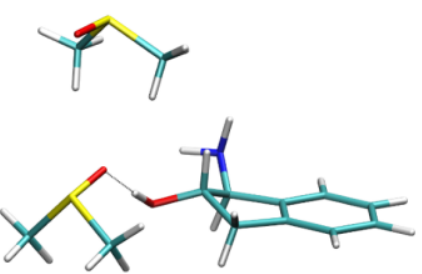

dmso-mono $\mathrm{OH}^{-\mathbf{e q}} g^{-} G^{-}: 4.9 \mathrm{~kJ} \cdot \mathrm{mol}^{-1}$

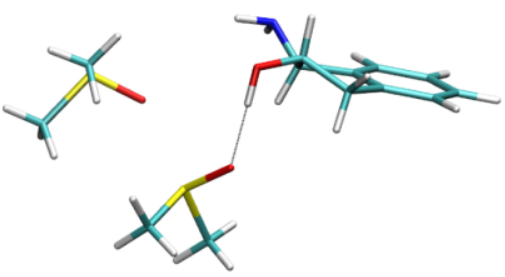

dmso-mono $\mathrm{OH}^{-\mathbf{e q}} t T: 6.4 \mathrm{~kJ} \cdot \mathrm{mol}^{-1}$

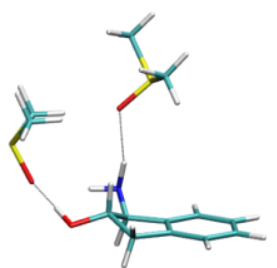

mono $_{\mathrm{OH}^{-}} \mathrm{mono}_{\mathrm{NH}}-\mathbf{e q} g^{+} \mathrm{G}^{-}: 8.3 \mathrm{~kJ} \cdot \mathrm{mol}^{-1}$

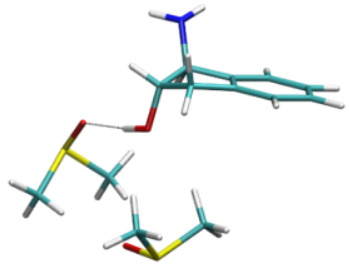

dmso-mono $\mathrm{OH}^{-}-\mathrm{ax}^{+} T: 16.9 \mathrm{~kJ} \cdot \mathrm{mol}^{-1}$

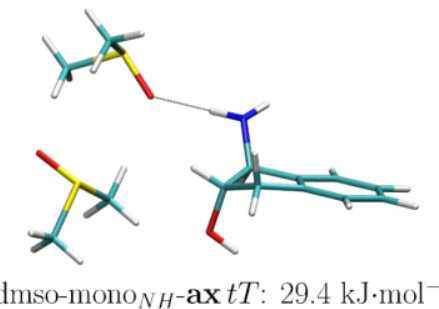

Figure S4: Stable calculated structure of the trans-AI:(DMSOd $)_{6}$ 1:2 complex at the B3LYP/6$311 \mathrm{G}++(d, p)$ level in a DMSO continuum. 

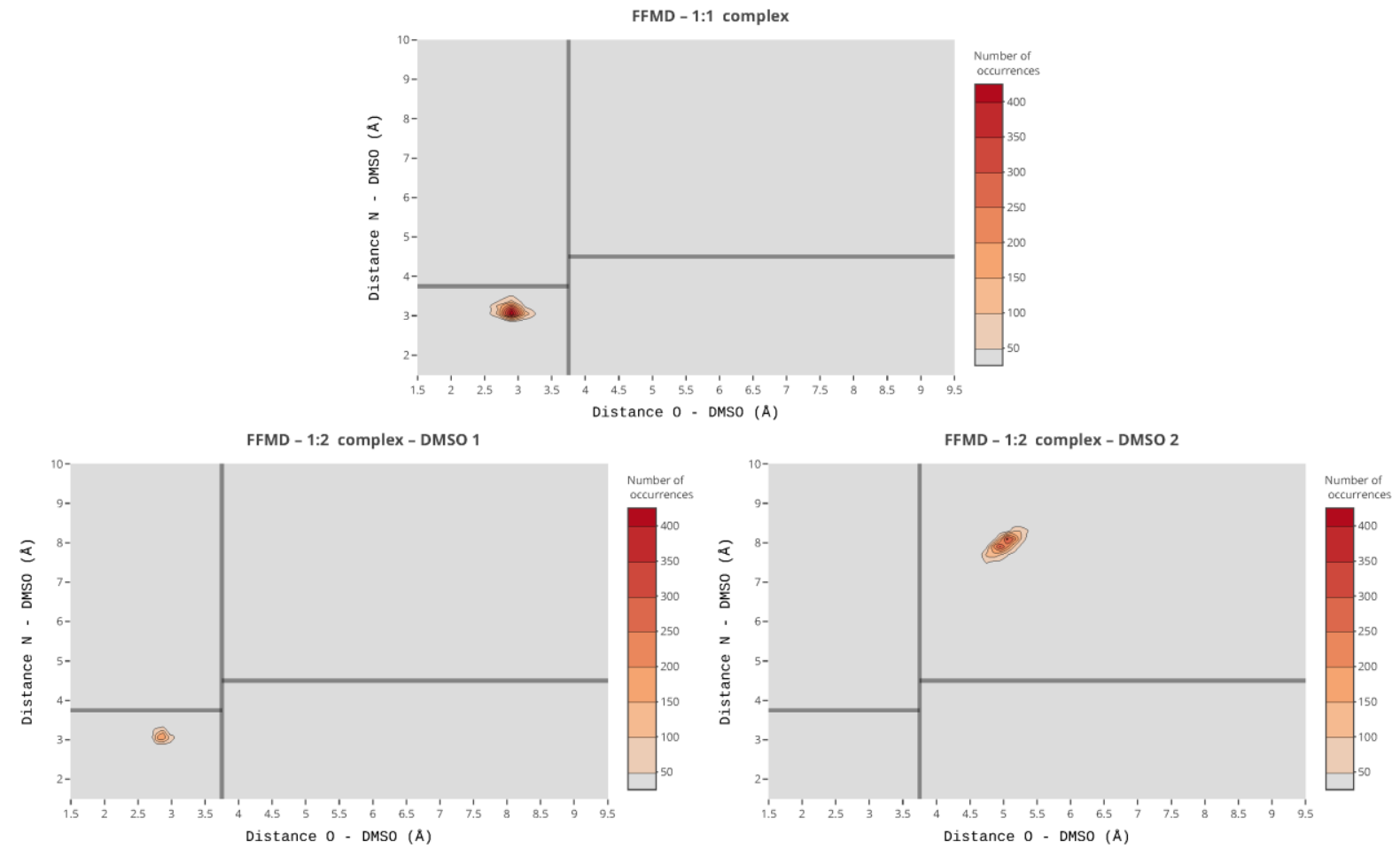

Figure S5: Contour plots of occurrence of O(trans-AI)-DMSO and N(trans-AI)-DMSO distances

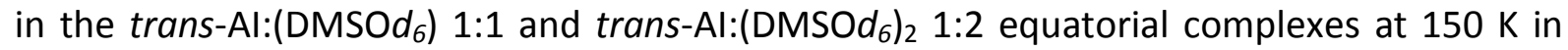
FFMD simulations.
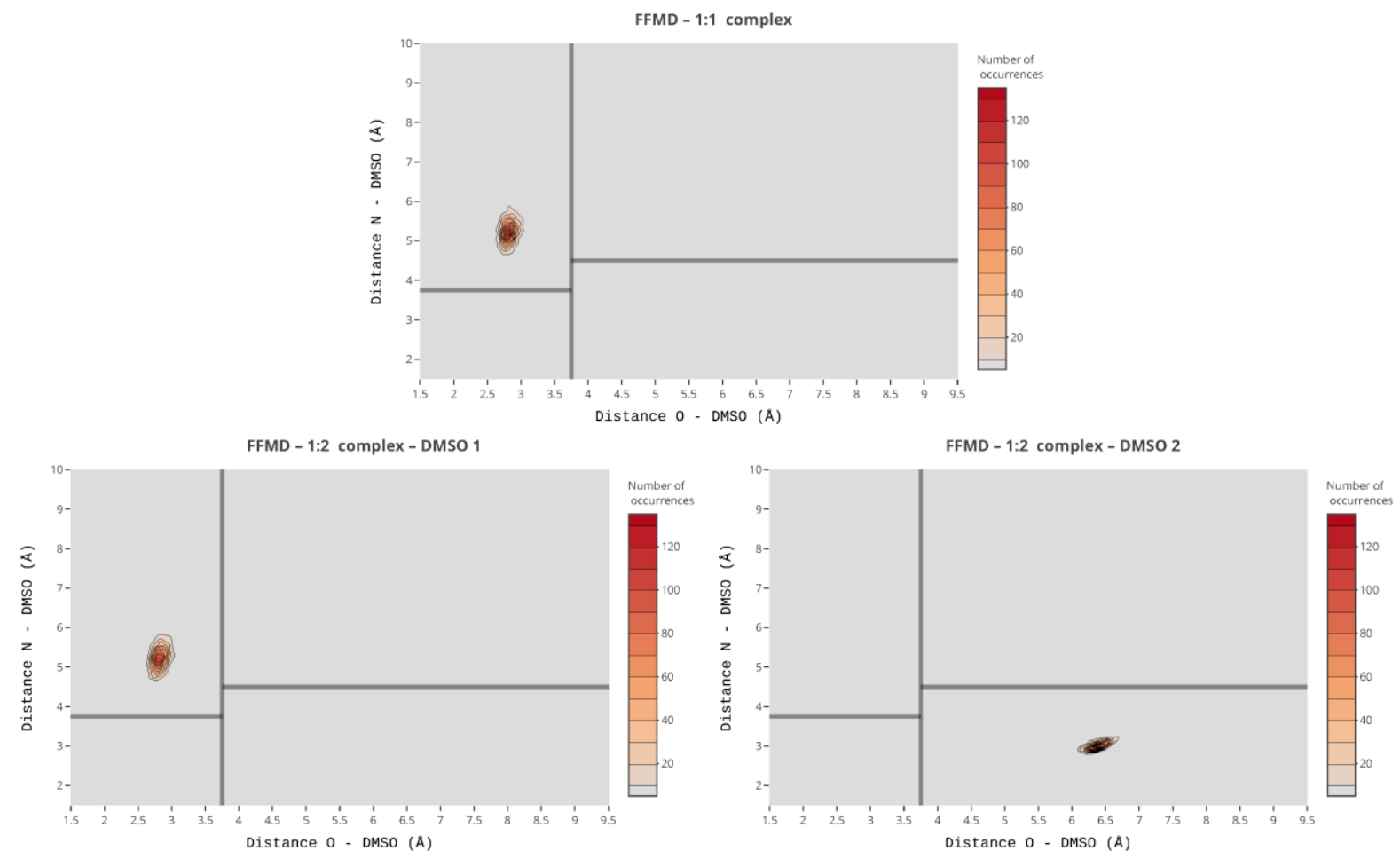

Figure S6: Contour plots of occurrence of O(trans-AI)-DMSO and N(trans-AI)-DMSO distances in the trans-Al:(DMSOd $\left.{ }_{6}\right)$ 1:1 and trans-Al:(DMSOd $\left.)_{2}\right)_{2} 1: 2$ axial complexes at $150 \mathrm{~K}$ in FFMD simulations. 

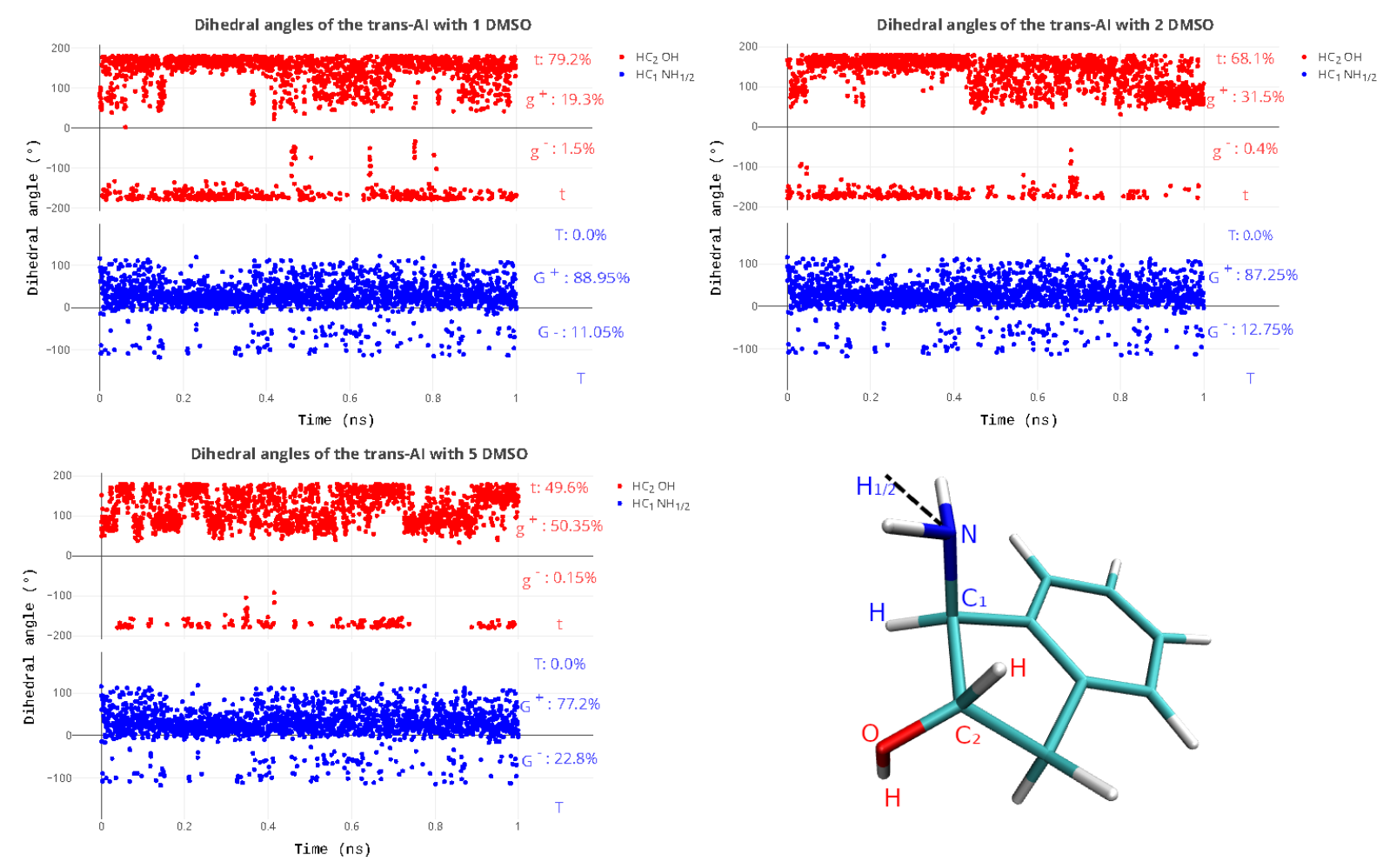

Figure S7: Dihedral angles describing the geometries of the hydroxyl (red) and amino groups (blue) of trans-Al during the FFMD simulations at $300 \mathrm{~K}$ with one, two and five DMSO. 

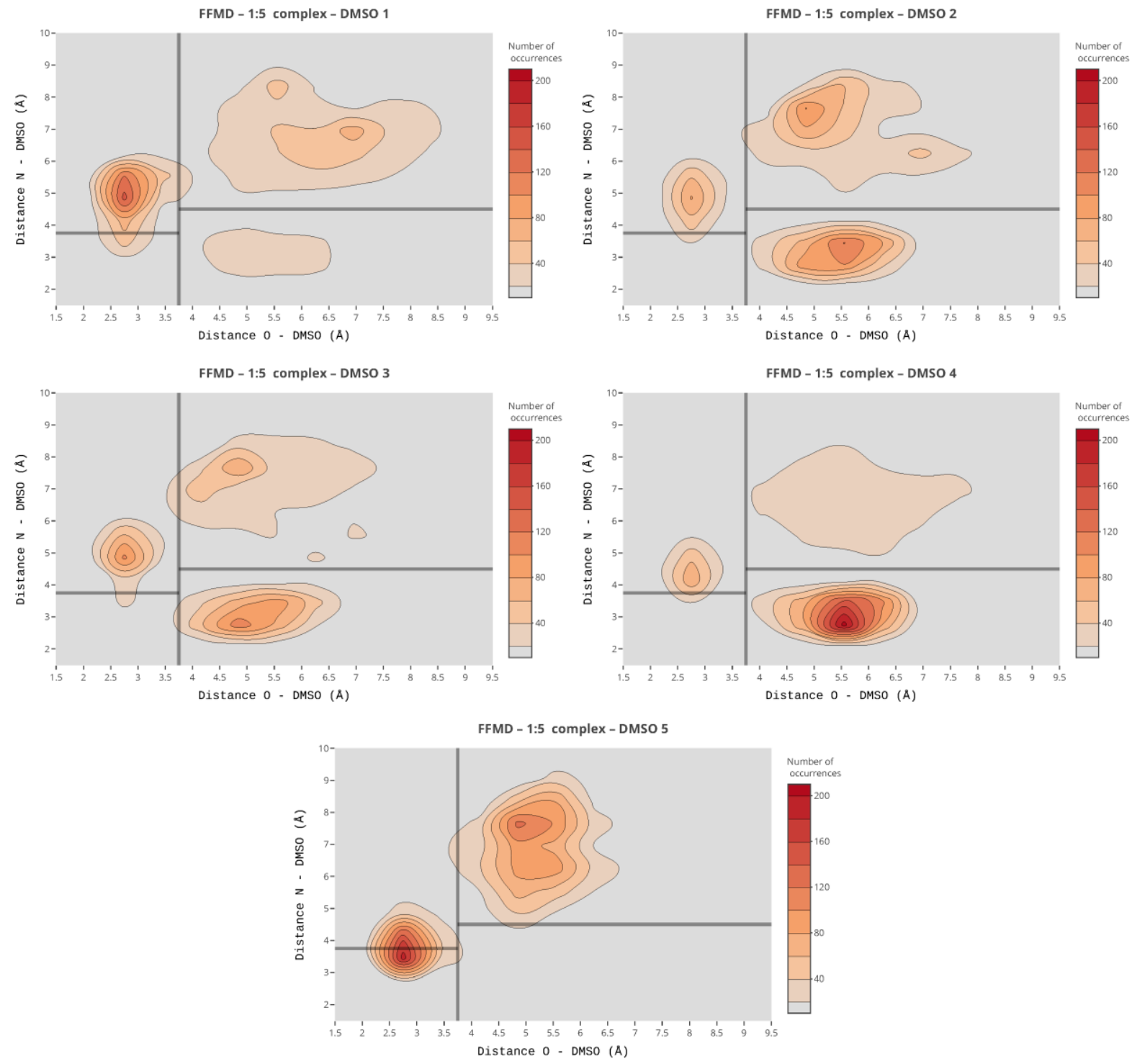

Figure S8: Contour plots of occurrence of O(trans-AI)-DMSO and N(trans-AI)-DMSO distances for the five DMSO molecules in the trans-Al:(DMSOd 6$)_{5}$ complex during the FFMD simulations at $300 \mathrm{~K}$. 

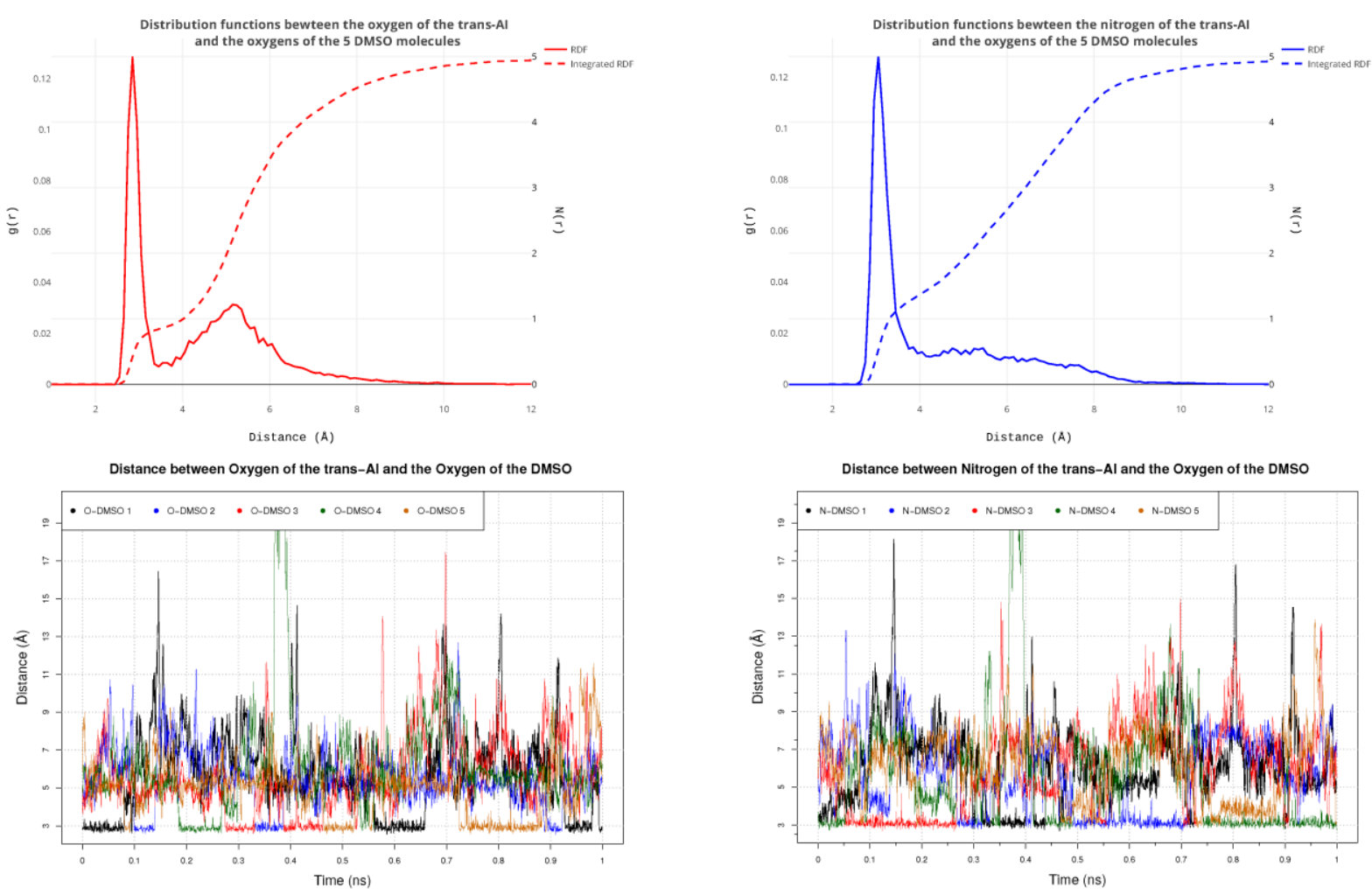

Figure 59: Radial distribution functions (RDF) (top) and distance evolution (bottom) as a function of time for the trans-Al:(DMSOd $)_{6}$ 1:5 complex at $300 \mathrm{~K}$, left: O(trans-AI)-O(DMSO), right: $\mathrm{N}($ trans-AI)- O(DSMO).
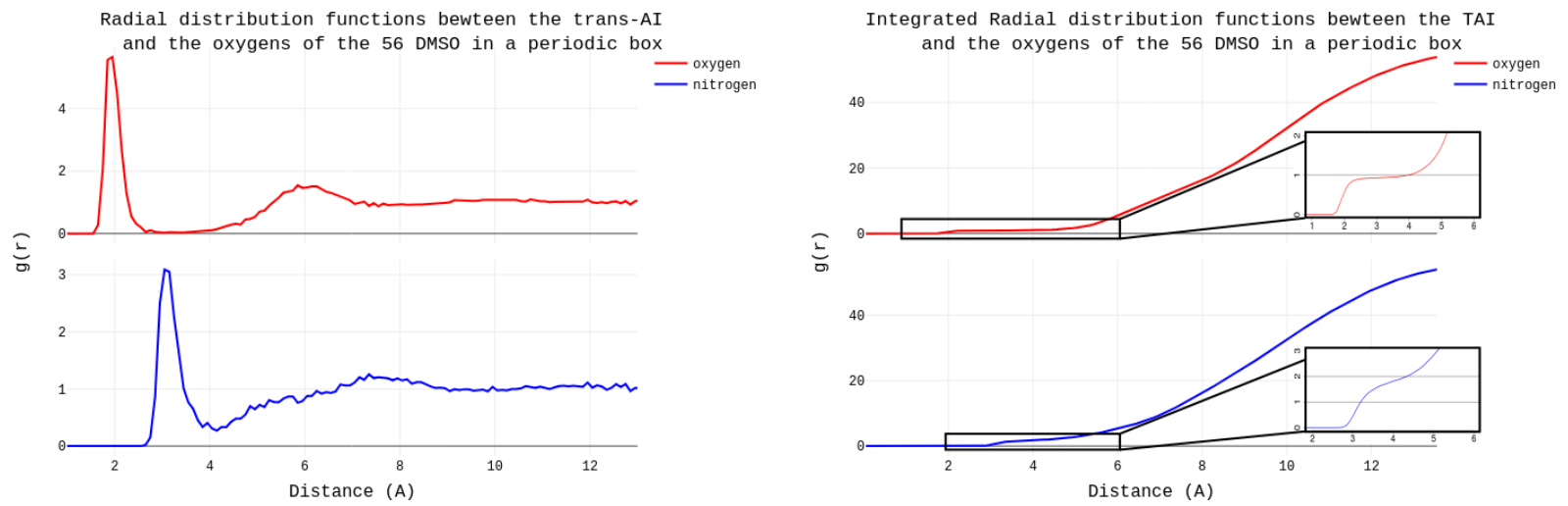

Figure S10: Radial distribution functions (RDF) for trans-Al in a box of 56 DMSO molecules at $300 \mathrm{~K}$. The RDF between the oxygen of the trans-Al and the DMSO molecules (red) shows an intense peak at $2 \AA$ while the RDF between the nitrogen and the DMSO molecules (blue) shows an intense peak at $3 \AA$. 


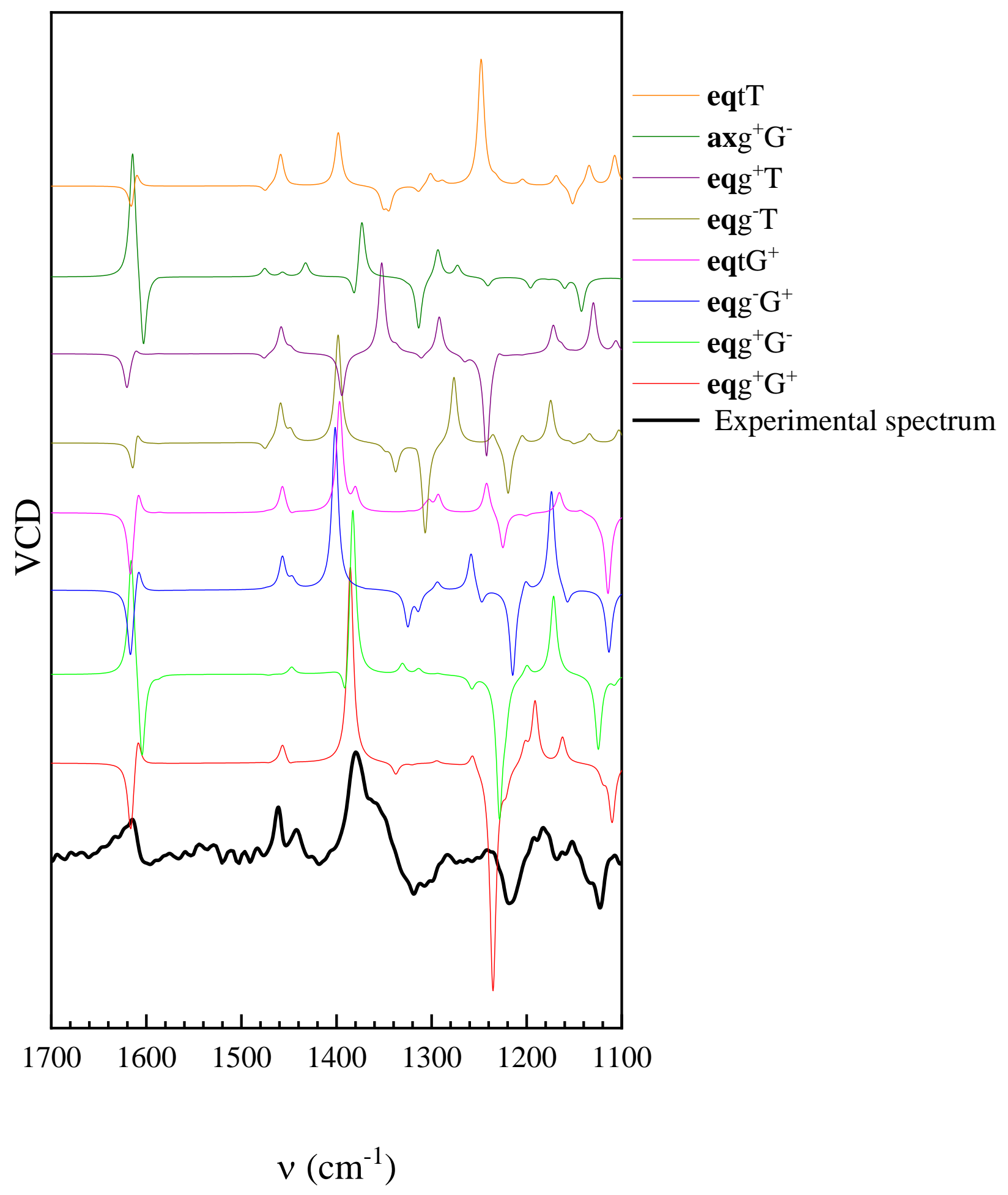

Figure S11: Simulated VCD spectra of the most stable conformers of $(S, S)$-trans-AI. 


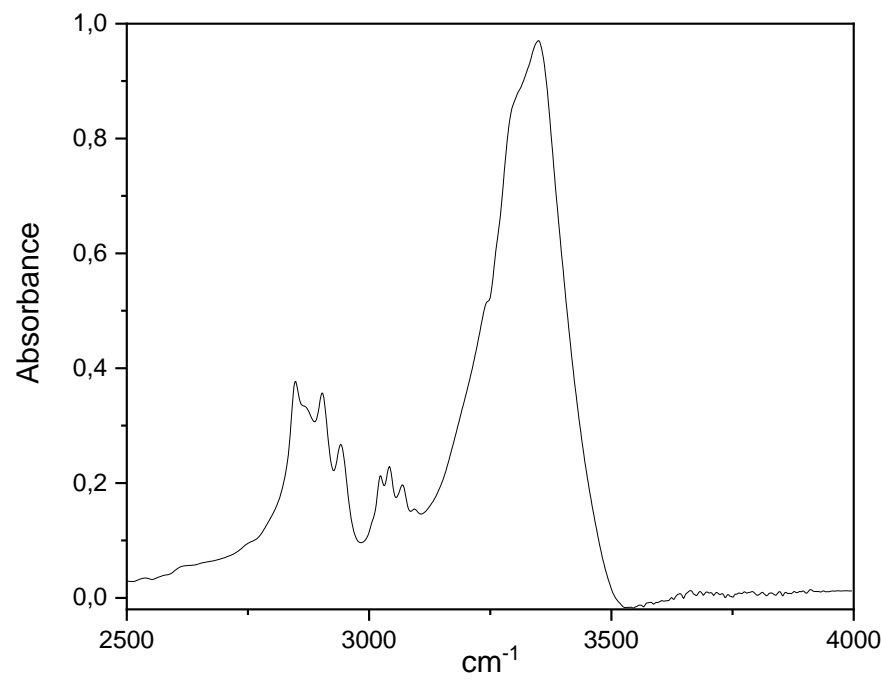

Figure S12: Absorption spectrum of trans-Al in a DMSO solution, in the $3 \mu \mathrm{m}$ region. 


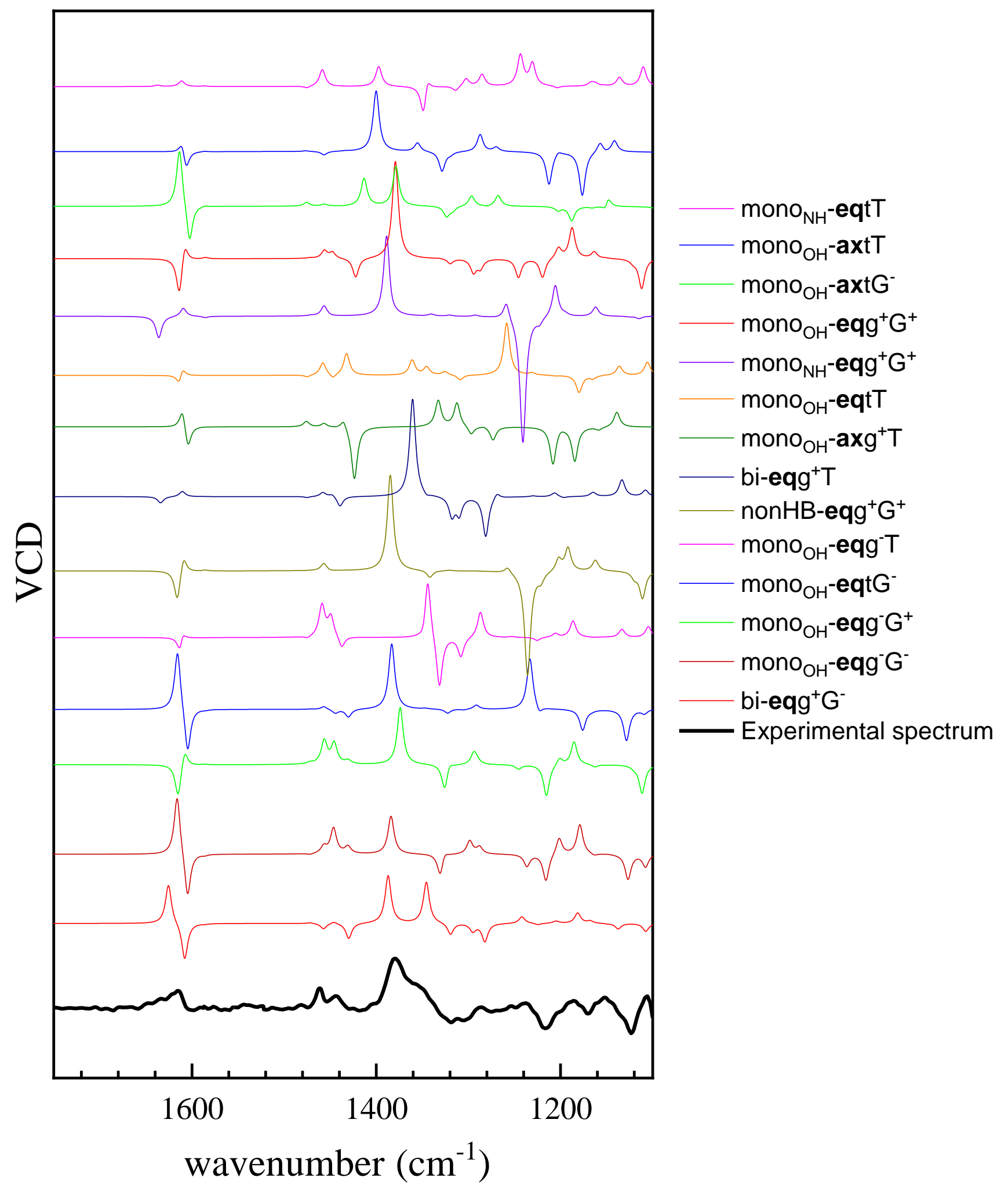

Figure S13: Simulated VCD spectra of the most stable conformers of the $(S, S)$-transAl:(DMSOd $\left.d_{6}\right) 1: 1$ complexes in a DMSO continuum calculated at the B3LYP/6-311++G(d,p) level. 


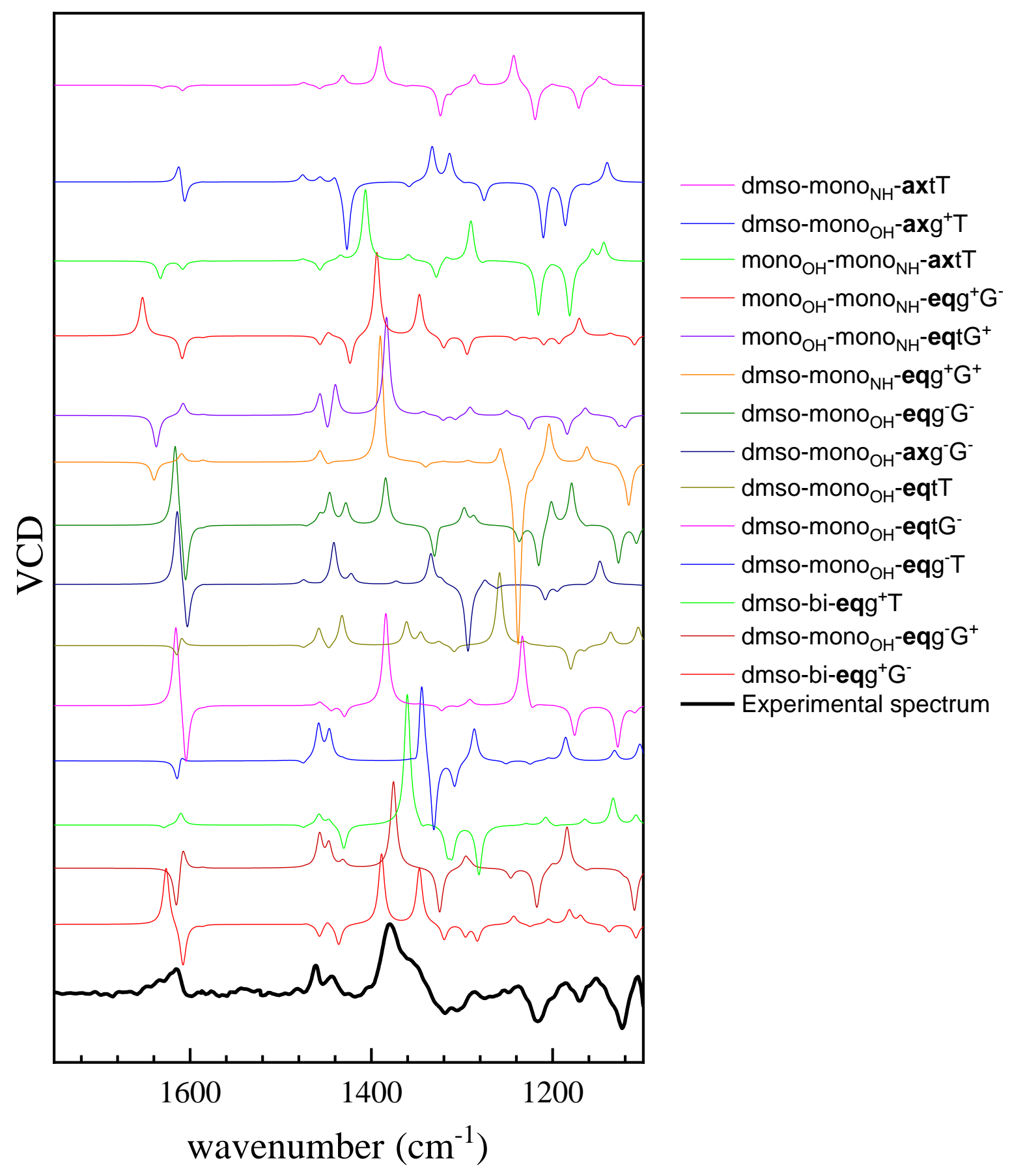

Figure S14: Simulated VCD spectra of the most stable conformers of the $(S, S)$ transAl:(DMSOd $)_{2}$ 1:2 complexes in a DMSO continuum calculated at the B3LYP/6-311++G(d,p) level. 


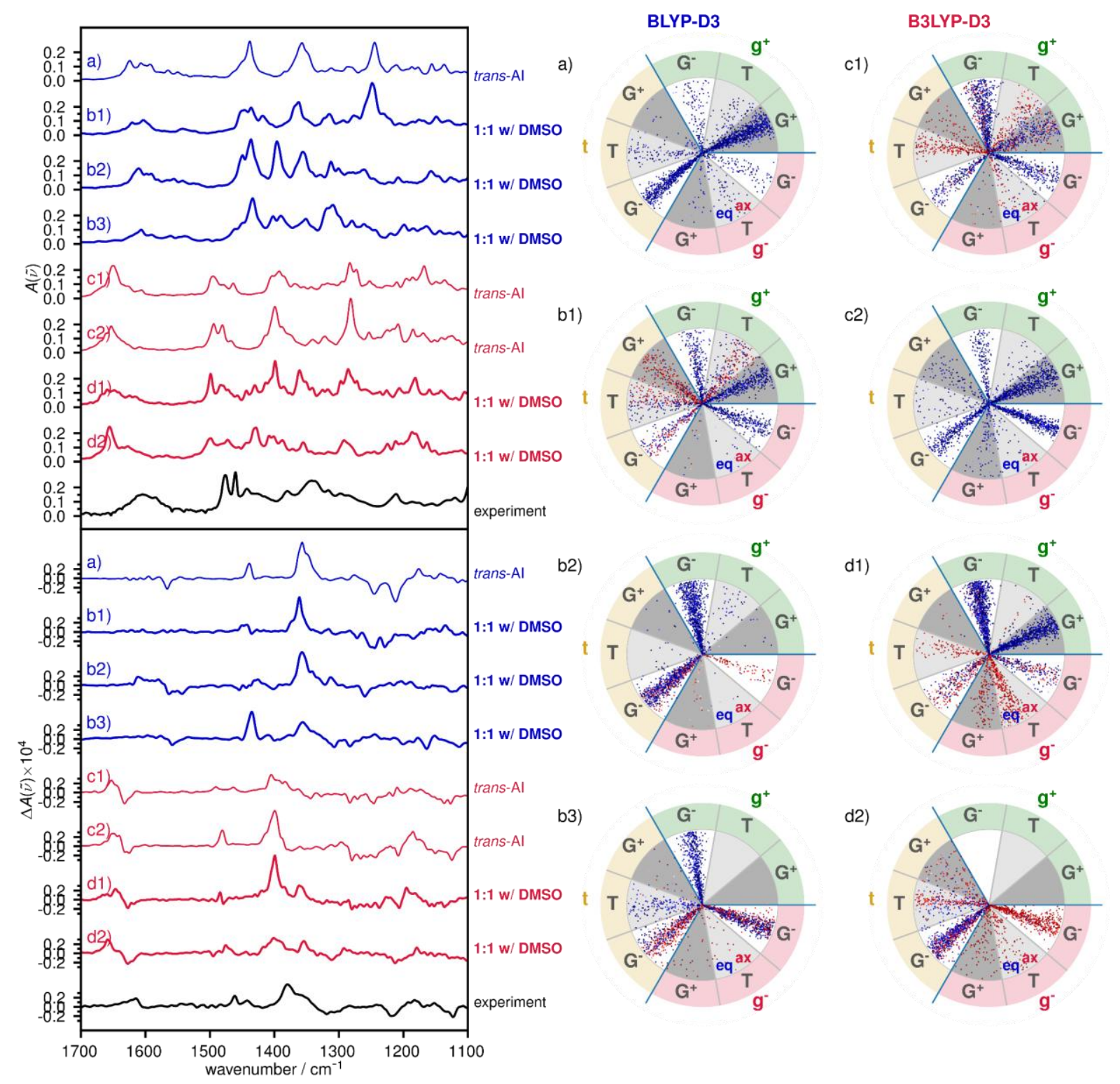

Figure S15: Left: IR and VCD spectra obtained for individual FPMD BLYP trajectories (blue colour) for the monomer (a) and the $1: 1$ complex $\left(b_{1}\right.$ to $\left.b_{3}\right)$, together with sampling clocks (right). Same for B3LYP trajectories (red colour) for the monomer $\left(c_{1}\right.$ to $\left.c_{2}\right)$ and the 1:1 complex $\left(d_{1}\right.$ to $\left.d_{2}\right)$. Sampling clock (right), displaying how the conformational space of $(S, S)$ trans-Al is visited by the FPMD trajectory. The circle is divided in regions of $\mathrm{OH}$ orientation and sub-divided in regions of $\mathrm{NH}_{2}$ orientation, using the notation of the static cluster analysis. The density of points is therefore proportional to the abundance of the corresponding conformation, whereas points in blue and red indicate equatorial and axial conformations, respectively. 
